\title{
The Role of Coherent Research-Based Curricular Unit in Mediating Students' Integrated Vision of Human Impact on the Environment
}

\section{Ghalichi, Narmin ${ }^{a}$ and Roehrig, Gillian ${ }^{a}$}

${ }^{\mathrm{a}}$ Department of Curriculum and Instruction, STEM track, University of Minnesota,

\begin{abstract}
The ongoing development of the high school ecology curricular unit presented in this proposal is a response to the new tide of educational reforms in the United States. This curricular unit represents an attempt to frame K-12 science curriculum around three dimensions: crosscutting concepts, disciplinary core ideas and scientific practices recently released in the report on a Framework for New K-12 Science Education (National Research Council, 2012). Integration of three dimensions into the development of agriculture-related curricular unit reflects complexity and logic inherent in science education facilitating deeper conceptual understanding. The development of this curricular unit takes place under the initiative of the National Science Foundation (NSF) funded project and explores the efficacy of the agriculture-related unit on students' integrated vision of the human impact on natural systems. Research project seeks to recognize the characteristics that identify research-based curriculum (Clements, 2007). The interdisciplinary nature of this project has the potential to investigate how close adherence to features identifying researchbased curriculum can support the development of coherent curricular unit mediating students' integrated vision of environmental issues. Mediation results of this nature have larger implications on future efficacy studies of curriculum intervention.
\end{abstract}

Keywords: Crosscutting concepts; constructivism; coherence; 'educativeness'; curriculum; environmental issues 


\section{Introduction}

The ongoing development of the curricular unit presented in this proposal is a response to the demand of framing K-12 science curriculum around multiple dimensions recently released in the report on a Framework for New K-12 Science Education (National Research Council [NRC], 2012), which served as a foundation for the development of Next Generation Science Standards (NGSS; NGSS Lead States, 2013). Human impact on natural systems is a section in the NRC Framework that includes examples of social systems that reflect the influence of human actions on the environment and require evidence-based decision-making in reducing the adverse effects of poor management of the limited planetary resources (NRC, 2012). The impact of intensive agriculture on the environment provides a relevant example of human-induced influence on natural systems communicated in current educational reforms and a real-life context to investigate mechanism underlying this interference. In this proposal we intend to explore critical features identifying agriculture-related research-based curriculum that informs connected scientifically based vision of environmental problems among high school students.

There is a pressing need to move from the ideology of constructivism to the development of research-based curriculum materials that are grounded in constructivist learning and are tightly aligned with three dimensions outlined in current educational reforms. The ongoing collaboration between the researcher and the high school biology teacher concentrates on the development of the coherent curricular unit to test correlation between critical features of research-based curriculum and students' integrated scientifically based vision of the agricultural impact on the environment as a result of curriculum implementation in spring, 2017.

\section{Critical Features Identifying Research-Based Curriculum}

The growing urgency for evidence-based curricular materials and the new wave of educational reforms emphasizing the integration of various dimensions of standards pose a challenge for addressing characteristics that identify research-based curriculum (Clements, 2007; Debarger et al., 2016). Adherence to these characteristics takes into account main general principles inherent in the framework proposed for the construction of researchbased curriculum in science education and mediates integrated understanding of the phenomena among students (Clements, 2007; Taylor et al., 2015). Current research proposal recognizes constructivism, coherence, and 'educativeness' as three characteristics identifying research-based curriculum (Taylor et al., 2015). 


\subsection{Adherence to Constructivism}

With the release of the new Framework for K-12 Science Education (NRC, 2012) and the Next Generation Science Standards (NGSS; NGSS Lead States, 2013) came the need to integrate three dimensions from NGSS: disciplinary core ideas, crosscutting concepts, and scientific practices (Debarger et al., 2016; Taylor et al., 2015). Researchers identify the unpacking of three dimensions of NGSS as the principal step in developing curriculum grounded in constructivist learning that reflects an expert view of how scientific ideas should be organized when using science standards as guidelines (Clements, 2007; Debarger et al., 2016; Krajcik et al., 2008; Taylor et al., 2015).

Recent re-emphasis in cognitive psychology on the active role students play in constructing knowledge individually and by interacting with social community has spawned a renewed interest toward constructivism and its potential in contributing to the process of curriculum development (Osborne, 1996). Constructivist learning employs strategies attending to general epistemology of knowledge construction, grounded in the empirically- based model of students' thinking (Clements, 2002; Sandoval \& Reiser, 2004). Despite the valuable contribution of constructivism to curriculum theory and practice, it can only be utilized to its full potential under ideal educational circumstances (Osborne, 1996; Terwel, 1999). Instructional models based on constructivist learning assist teachers in scaffolding learning activities for students and creating ideal educational opportunities for meaningful learning to occur (Krajcik et al., 2008; Taylor et al., 2015).

\subsection{Adherence to Coherence}

In promoting coherence curriculum developers arrange learning activities within coherent conceptual framework that reflects the logic of the science discipline from which the subject matter derives (Schmidt et al., 2005; Taylor et al., 2015). Development of conceptual framework is a principal step in ensuring coherent flow of discipline specific scientific ideas consistent with constructivist learning (Taylor et al., 2015). Adherence to conceptual framework becomes instrumental in integrating disciplinary core ideas highlighted by NGSS and in coordinating learning goals, cognitive tasks and assessments. One of the ways of strengthening coherence of the curriculum development process is the use of conceptual flow graphics (CFGs) (Taylor et al., 2015). Curriculum developers use CFGs to overlay a constructively arranged sequence of cognitive tasks with disciplinary core ideas creating conceptual storyline (Fig. 1). 


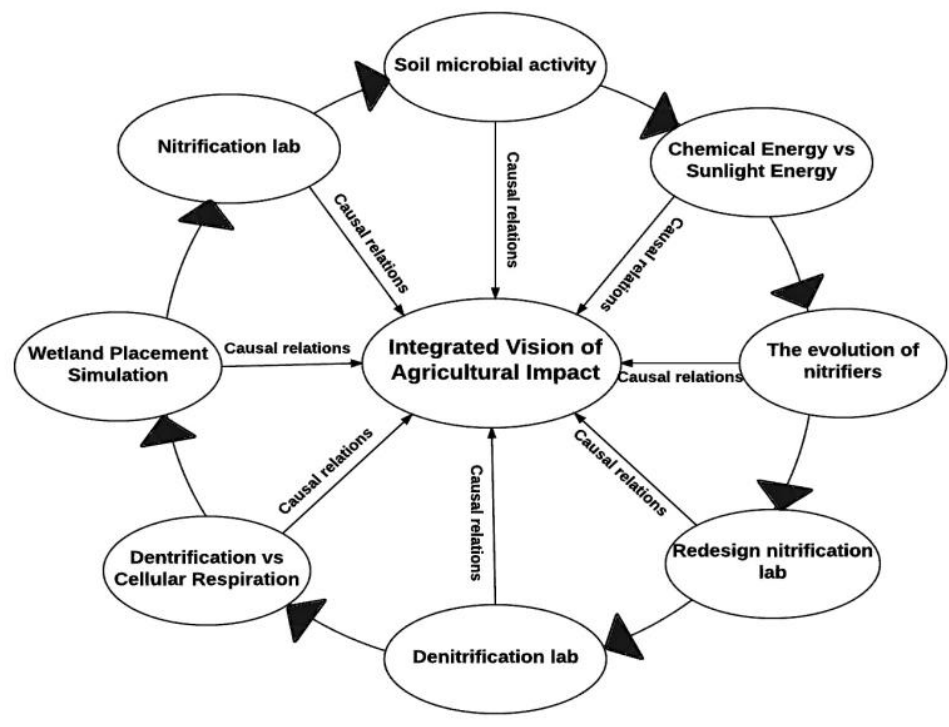

Figure 1. Conceptual Flow Graphic (CFG) of the activities in the curricular unit advancing the crosscutting concept by exploring causal relations

\subsection{Adherence to 'Educativeness' of Curriculum Materials}

To ground the discussion on 'educativeness' of curriculum materials, we will focus on the explicit teacher support for learning, such as pedagogical support, which is embedded in the curricular materials (Schneider \& Krajcik, 2002; Taylor et al., 2015). Current research points to the imminent tension arising as a result of having to incorporate particular curriculum without clear pedagogical support (Krajcik et al., 2008; Taylor et al., 2015). To mitigate this tension, researchers list suggestions in the format of heuristics serving the purpose of supporting teachers as they implement the curriculum materials as intended (Davis \& Krajcik, 2005).

These heuristics promote 'educativeness' of curricular materials by providing specific content, skills, topics, suggestive timeline, a pedagogical model as well as instructional strategies on dealing with potential student misunderstanding (Remillard, 1999; Schneider $\&$ Krajcik, 2002; Taylor et al., 2015). To that extent educative materials provide teachers with pedagogical support by including help in understanding the sequence and flow of the curricular materials (Schneider \& Krajcik, 2002). 


\section{Carving the Space for Collaboration}

Despite the clear advantages of educative curricular materials, professional development and collaboration provide opportunity for teachers to study materials thus increasing teachers' knowledge of the rationale underlying instructional decisions embedded in the curricular materials (Taylor et al., 2015). The need for professional development or collaborative learning opportunities becomes critical when curricular units include the use of computer-based simulation (Webb, 2005). To avoid teachers' withdrawal from their teaching roles and overreliance on the software simulation, teachers need to engage in questioning students to assess their understanding of the simulation use (Sandoval \& Reiser, 2004; Webb, 2005). Development work with teachers promotes higher level of engagement, which leads to frequent interactions with simulation and teachers' improved ability to design tasks and questions that would promote student thinking (Webb, 2005). Therefore, professional development and collaborative learning with the curriculum developers carve the space for teachers to interact with the educative nature of curricular materials and to take full advantage of research-based curriculum materials. These collaborative learning opportunities and educative provisions should account for potential difficulties that teachers face when adapting curriculum materials into their existing curricular repertoire (Davis \& Krajcik, 2005; Remillard, 1999).

\section{Attendance to Critical Features During the Development of Agriculture- Related Unit}

The agriculture-related curricular unit presented in this paper coordinates learning goals, cognitive tasks and assessments around NGSS dimensions and exemplifies a tension between social system and the environment (NRC, 2012). The significance of sound understanding of environmental problems becomes central for citizen participation in addressing issues stemming from human interference with natural systems (Mohan et al., 2009; Gunckel et al., 2012). Therefore, in order to gain agency in evidence-based decisionmaking on environment-related issues from a scientific perspective, students need to develop understanding of causal relationships among entities implicated in the negative impact of the agricultural production on ecological systems (Gunckel et al., 2012; Williamson, 2011).

\subsection{Research-Based Unit Consistent with Constructivist Learning}

As a part of the NSF sponsored research project, the proposed agriculture-related curricular unit stems from the collaborative efforts between the researcher and the high school biology teacher whose ecology class will participate in the unit implementation in spring semester 2017. In attending to constructivist learning during the development of the curricular materials, central curricular components are framed within the 5E Instructional Model 
(engage, explore, explain, elaborate, and evaluate) (Taylor et al., 2015). Consistent with the principles of constructivism, the initial learning activity serves the purpose of anchoring students' interest. Throughout the sequence of following cognitive tasks students can isolate causal relationships by applying the canonical strategy of controlling variables and eliciting general epistemological commitments of constructivism that are reflected in the crosscutting concept of cause and effect in NGSS (Sandoval \& Reiser, 2004).

\subsection{Coherent Storyline in Research-Based Unit}

Although general epistemological commitments are consistent with principles of constructivism, they lack the knowledge on what particular discipline specific variables to control (Sandoval \& Reiser, 2004). Cognitive tasks of this unit intend to overlay crosscutting concepts of cause and effect with disciplinary core idea of agricultural impact and contribute to the overall coherence reflected in the curricular unit. The overarching goal of the curricular unit aims to emphasize causal relations among entities implicated in the agricultural impact on the environment. As a result of this coherent curricular sequence, ecology high school students establish evidence-based causal relations among entities in mapping out connection between nitrogen and carbon cycles as a mechanism implicated in the impact of intensive agriculture on ecological systems (Mohan et al., 2009; Gunckel et al., 2012; Williamson, 2011). Such an approach intends to facilitate students' understanding of lower level activities and encourage students to use causal relations to construct evidence-based explanation about higher-level observable phenomenon (Williamson, 2011). By unraveling discipline specific causal relationships students establish the link between invisible micro processes and observable patterns at macro-scale, and mediate integrated understanding of feedback mechanisms bringing natural systems back to stability (Fig.1).

\subsection{Educative Curricular Materials and Collaboration Lead to Enhanced Pedagogical support}

The ongoing collaboration between the high school biology teacher and the researcher has been critical in helping the teacher develop more content specific knowledge on ecological concepts that the teacher previously considered outside of her expertise area. This collaborative experience provided the teacher with opportunities to study the materials and to make instructional decisions regarding the arrangement of the cognitive tasks, instilling the teacher with the sense of ownership of the curriculum materials that will be implemented in spring 2017 (Davis \& Krajcik, 2005; Schneider \& Krajcik, 2002).

The critical importance of collaboration between the teacher and the researcher has been especially pronounced during the collaborative development of questions and tasks to accompany a software simulation exploring the effectiveness of wetland construction. This 
computer-based simulation results from the partnership between U-spatial software engineers and St. Anthony Falls Laboratory at the University of Minnesota. Research indicates the advantage of using computer-based simulations in manipulating variables that are outside of user's control in the natural world (Huppert et al., 2002; Trey\& Khan, 2008). To such extent the use of this computer simulation intends to promote students' sense of agency in implementing the best land use management practices. At the same time, the effective use of computer simulation is closely connected to the teacher guidance that supports the simulation use (Sandoval \& Reiser, 2004; Webb, 2005). The ongoing collaboration with an active involvement of an expert scientist aims to develop a set of questions and tasks to facilitate students' ability in constructing explanations on wetland effectiveness by eliciting evidence-based causal links highlighted throughout the curricular sequence. These collaborative learning opportunities with curriculum developers enable the teacher to capitalize on the embedded educative nature of the unit materials and to participate in the development of cognitive tasks that encourage evidence-based vision of environmental issues.

\section{Significance}

This research project intends to explore the extent to which synergistic arrangement of cognitive tasks in the research-based curricular unit strengthened by pedagogical support and collaborative opportunities assists teachers with mediating integrated students' vision of human-induced impact on the environment. The uniqueness of this study stems from testing the impact of coherent agriculture-related curricular unit encouraging students to explore causal links among entities in mapping out the interactive nature of nutrient cycles underlying the human interference with natural systems. The interdisciplinary nature of this project has the potential to show how close adherence to features identifying researchbased curriculum and collaborative learning opportunities can support development of coherent curricular unit mediating students' integrated vision of environmental issues. Having coherent curriculum materials consistent with educational reforms and a teacher prepared to use these materials in an intended manner are critical in enacting opportunities that mediate considerable impact on students' conceptual understanding. Mediation results of this nature have larger implications on future efficacy studies of curriculum intervention. 


\section{References}

Clements, D. H. (2002). 23 linking research and curriculum development.

Clements, D. H. (2007). Curriculum research: Toward a framework for "research-based curricula". Journal for Research in Mathematics Education, 35-70.

Davis, E. A., \& Krajcik, J. S. (2005). Designing educative curriculum materials to promote teacher learning. Educational Researcher, 34(3), 3-14.

Debarger, A. H., Penuel, W. R., Harris, C. J., \& Kennedy, C. A. (2016). Building an assessment argument to design and use next generation science assessments in efficacy studies of curriculum interventions. American Journal of Evaluation, 37(2), 174-192.

Gunckel, K. L., Covitt, B. A., Salinas, I., \& Anderson, C. W. (2012). A learning progression for water in socio-ecological systems. Journal of Research in Science Teaching, 49(7), 843-868.

Huppert, J., Lomask, S. M., \& Lazarowitz, R. (2002). Computer simulations in the high school: Students' cognitive stages, science process skills and academic achievement in microbiology. International Journal of Science Education, 24(8), 803-821.

Krajcik, J., McNeill, K. L., \& Reiser, B. J. (2008). Learning-goals-driven design model: Developing curriculum materials that align with national standards and incorporate project-based pedagogy. Science Education, 92(1), 1-32.

Mohan, L., Chen, J., \& Anderson, C. W. (2009). Developing a multi-year learning progression for carbon cycling in socio-ecological systems. Journal of Research in Science Teaching, 46(6), 675-698.

National Research Council. (2012). A framework for K-12 science education: Practices, crosscutting concepts, and core ideas. Washington, DC: National Academy Press.

NGSS Lead States. (2013). Next Generation Science Standards: For states, by states. Washington, DC: National Academies Press.

Osborne, J. (1996). Beyond constructivism. Journal of Research in Science Teaching, 80(1), 53-82.

Remillard, J. T. (1999). Curriculum materials in mathematics education reform: A framework for examining teachers' curriculum development. Curriculum Inquiry, 29(3), 315-342.

Sandoval, W. A., \& Reiser, B. J. (2004). Explanation-driven inquiry: Integrating conceptual and epistemic inquiry. Science Education, 88(3), 345-372.

Schmidt, W. H., Wang, H. C., \& McKnight, C. C. (2005). Curriculum coherence: An examination of US mathematics and science content standards from an international perspective. Journal of Curriculum Studies, 37(5), 525-559.

Schneider, R. M., \& Krajcik, J. (2002). Supporting science teacher learning: The role of educative curriculum materials. Journal of Science Teacher Education, 13(3), 221-245.

Taylor, J. A., Getty, S. R., Kowalski, S. M., Wilson, C. D., Carlson, J., \& Van Scotter, P. (2015). An efficacy trial of research-based curriculum materials with curriculum-based professional development. American Educational Research Journal, 52(5), 984-1017.

Terwel, J. (1999). Constructivism and its implications for curriculum theory and practice. Journal of Curriculum Studies, 31(2), 195-199. 
Trey, L., \& Khan, S. (2008). How science students can learn about unobservable phenomena using computer-based analogies. Computers \& Education, 51(2), 519-529.

Webb*, M. E. (2005). Affordances of ICT in science learning: Implication for an integrated pedagogy. International Journal of Science Education, 27(6), 705-735.

Williamson, J. (2011). Mechanistic theories of causality part I. Philosophy Compass, 6(6), 421-432 